\title{
Dynamic Analysis and Vibration of Beam Inside Annulus for Ultra Short-Radius Water Jet Drilling
}

\author{
T Pervez ${ }^{*}$, SA Al-Hiddabia, A Al-Yahmadia and AC Seibi ${ }^{b}$ \\ ${ }^{*}$ a Department of Mechanical and Industrial Engineering, College of Engineering, Sultan Qaboos University, \\ P.O. Box 33, Postal Code 123, Al-Khoud, Muscat, Oman \\ ${ }^{b}$ Petroleum Institute, Abu-Dhabi, UAE
}

Received 3 October 2010; accepted 17 May 2011

\begin{abstract}
Conventional water-jet nozzle systems have been developed and partially used in the oil and gas industry to drill horizontal sidetracks. However, this technique still presents a few shortcomings associated with tube buckling and water jet sagging. Due to these problems, the drilled hole deviates from the desired path and does not reach the target reservoir. The issue becomes more complex due to the continuously moving boundaries representing the borehole profile, which is, in turn, governed by the nozzle dynamics. A mathematical model representing the dynamics of water jet drilling confined in a borehole along with drilling mud is developed to predict the sagging phenomenon during the drilling process. The closed form solution of the governing equation is obtained for horizontal drilling in shallow formation layers. The solution shows the strong influence of nozzle vibration and the magnitude of thrust force at the nozzle tip on the profile and the diameter of drilled hole. For sidetrack drilling of greater than 400 $\mathrm{m}$ length, the magnitude of sagging is large enough to miss the target reservoir. Furthermore, the drill string buckles at certain magnitudes of thrust forces and penetration lengths.
\end{abstract}

Keywords: Ultra short radius, Water-jet drilling, Dynamics and control

$$
\begin{aligned}
& \text { التحليل الديناميكي والاهتزازي لأنبوب الحفر باستخدام تكنولوجيا الحفر بالماء المضغوط في الحفر ذات الأقطار } \\
& \text { القصيرة. } \\
& \text { ت. برفيزهأ ، س. أ . الهدابي ، أ. اليحمدي أو أ.س. سيبي }
\end{aligned}
$$

الملخص: تم تطوير أنظمة الحفر الأفقي باستخدام المياه المضغوطة واستخدامها بشكل جزئي في صناعة النفط والغاز. ولككن ما يزال هذا النظام النظام يعاني

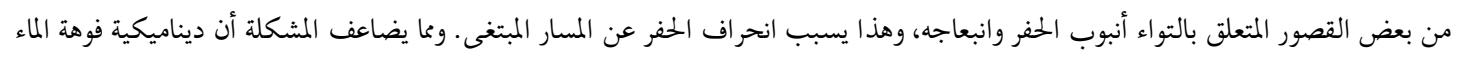

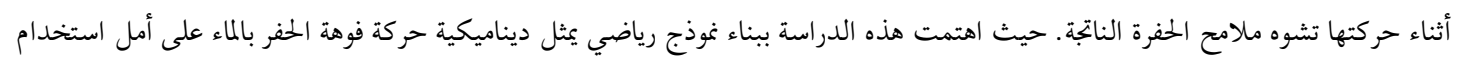

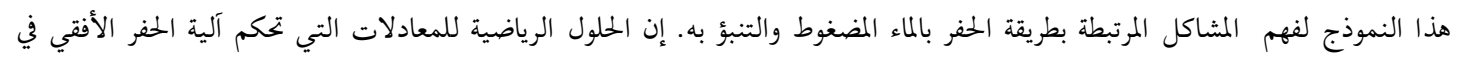

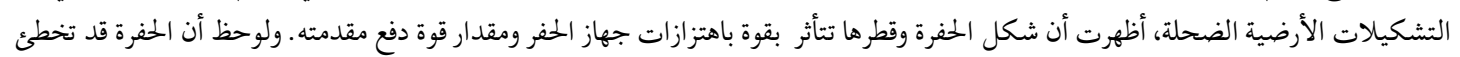

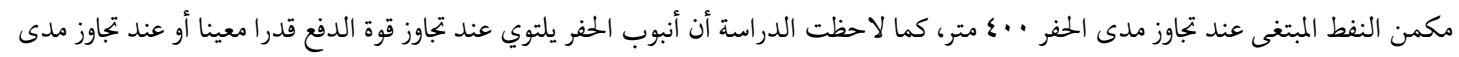
الحفر طولا معينا. الكلمات الدالة: نصف القطر المتناهي الصغر، الحفر باستخدام الماء، الديناميكا والتحكم

\section{Introduction}

Recently, the oil and gas industry has witnessed a steady increase in the use of short-radius horizontal drilling operations to enhance well productivity. The trend is expected to continue in the future as oil and gas industries become increasingly aware of the benefits associated with it while targeting thin reservoirs and oil reserves which are pocketed and scattered. Cost savings and simplicity are the major driveing factors in developing the technology and tools to drill sidetracks of short or ultra-short radius. Furthermore, the rapid decrease in active reserves, the ever increasing difficulty of exploratory development of the matured fields and the transfer of exploration targets from conventional reservoirs to unconventional ones with low permeability, low pressure and low productivity pose new challenges to the drilling technique

*Corresponding author's e-mail: tasneem@squ.edu.om 
and technology (Zhu 2009). It is often much cheaper to initiate a lateral or sidetrack from an existing wellbore to reach small pockets of reserves rather than drilling a new well. Recent use of short-radius drilling has resulted in an enhanced production of depleted fields in south Asia. The operator of a mature offshore oil field has significant production increase, when over 100 short-radius wells have been drilled as a re-development project to access bypassed reserves (Halliburton 2009).

Horizontal and multilateral wells are the direct results of the advances in directional drilling which have allowed operators to select the most appropriate well profile, geometry and entry points. These wells have an edge over the conventional vertical wells in terms of ultimate recovery in many marginal wells. The productivity of horizontal and multilateral wells can be estimated using the semi-analytical model developed by (Tabatabaei, Ghalambor 2009). It is believed that these multilaterals will perform better in thin reservoirs, double porosity and discreetly fractured reservoirs, reservoirs with anisotropic vertical permeability and in various enhanced oil recovery concepts. However, it is more expensive to drill and complete such a well. Hence, there is a need to develop an economical, reliable and simple technology to drill sidetracks.

Current technology for drilling provides a number of systems to generate short-radius drilling such as the "conventional" coil-tubing drilling system (Kolle, Marvin 2000), the flexible pipe rotary steerable system (LaPrade 2000), the water jet drilling system (Dickinson et al. 1990) and the coiled tubing conveyed drilling technique (Buset et al. 2001). The goal is to improve the production profile around the mother well by penetrating the thin reservoirs and hydrocarbon pockets behind or surrounding the actual reservoir. For horizontal sidetracks of ultra short-radius ie., a radius of curvature smaller than 4 meters or less, the water jet drilling system seems to be a viable option (Kolle 1998). In the last two decades, the conventional water-jet nozzle system has been developed and used to cut, machine, and drill or fracture several target materials such as metals, ceramics, and rocks (Fair 1998). The system worked satisfactorily for metals and ceramics as it has received the proper attention of researchers and technology developers. However, a few shortcomings need to be overcome before the oil and gas industry will accept this as an alternative in directional drilling of sort and ultra short-radius sidetracks.

The two major challenges associated with the water jet drilling system are tube buckling and the sagging of the water jet which results in a deviation from the desired path. It has been observed that within few tens of meters, the tubing moves downward through the formation due to sagging (Stoner 1999). Due to the tube sagging, drilling in a thin oil-sand layer becomes problematic resulting in missing the desired target. Therefore, it is important to predict the path a of drilled hole in order to achieve effective and efficient use of the water jet drilling system before undertaking any drilling activities. A better understanding of the sagging phenomenon is crucial for designing such a drilling system with an embedded directional control to minimize the deviation between the drilled hole and the desired target. The current work focuses on studying the dynamics of a water jet drilling system during horizontal drilling. The developed model is able to predict the profile of a drilled hole and identifies the important parameters which contribute to the sagging phenomenon.

\section{Problem Description}

The water jet drilling system under study consists of a tube with a nozzle attached at its end. The tube is pushed axially to set it initially at a prescribed location to start drilling the hole. The water jet shooting out of the nozzle at a very high velocity does the drilling. This results in a hole with a diameter greater than the tube diameter which makes it easy for the tube to penetrate through the formation until the desired length of the drilled hole is attained. Then the tube is clamped at the kick-off point from where it can be pushed forward and can drill the hole, as shown in Fig. 1 while the nozzle end is free to move. This allows the tube and nozzle system to be modeled as a cantilever beam. The tube geometry is uniform and is made of homogenous and isotropic material. The borehole geometry will depend on the lateral displacement and velocity of the nozzle. It is assumed that, during drilling operation, there is some clearance between the hole and the tube diameter which will restrict the deformation of the drilling tube within elastic region. In addition, the lateral vibration of the tube will be constrained by the borehole. The axial dynamics of the system was modeled as a quasi-static problem. Due to these effects, the developed mathematical model is not only complex but also nonlinear in nature. In addition the system is modeled as a continuous medium, resulting in partial differential equations describing the lateral dynamics of the jetting system.

\subsection{Governing Equation}

The governing equations of the tube are derived by considering an infinitesimal section of the tube, as 


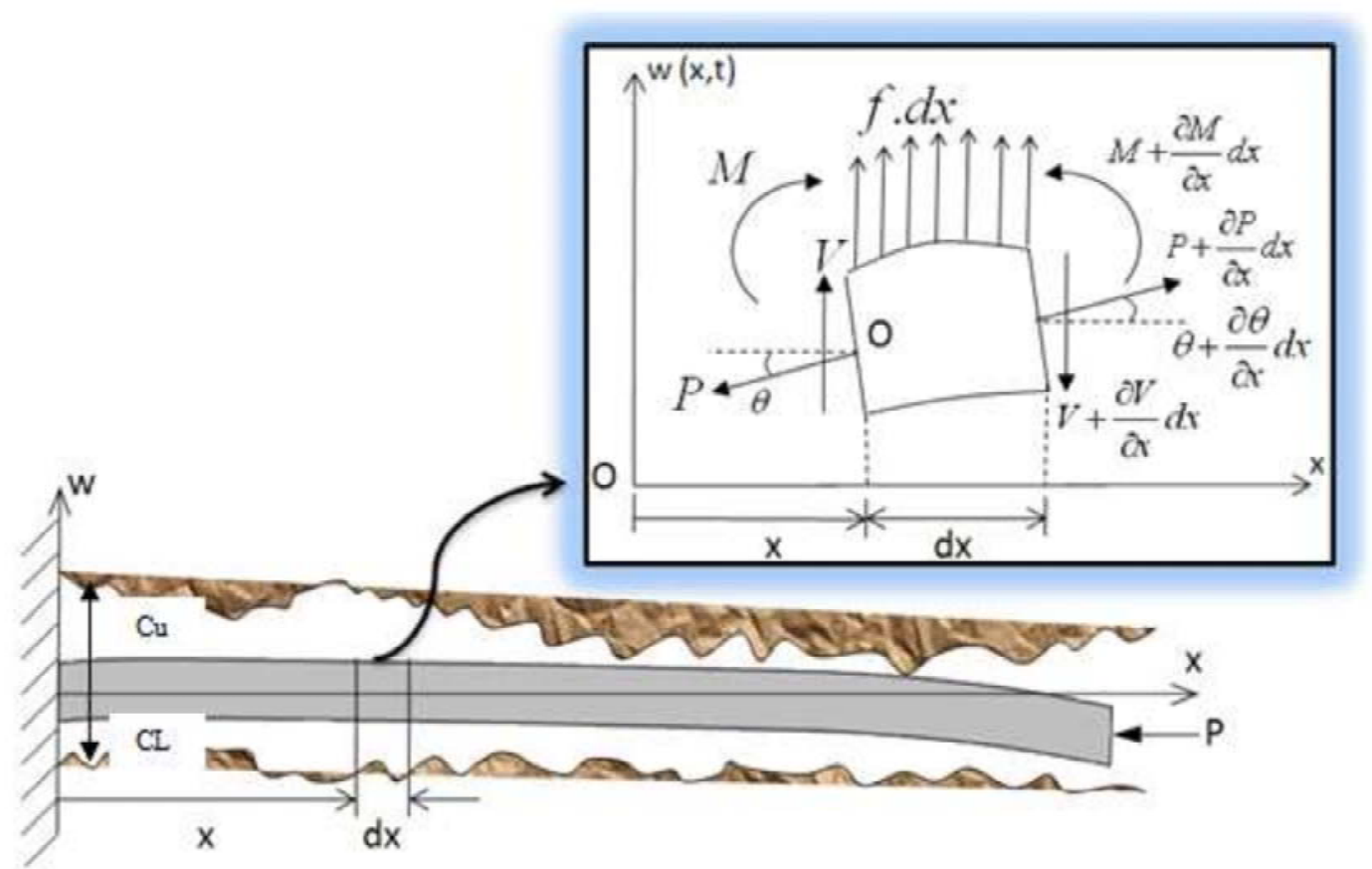

Figure 1. Free body diagram of an infinitesimal element of drilling tube

shown in Fig. 1, with the surrounding hole at a distance ' $\mathrm{x}$ ' from the left end, which represents the starting point of drilling. Using the force equilibrium and moment equilibrium, the equation of motions for the infinitesimal tube element can be written as:

$-(V+d V)+f d x+V+(P+d P) \sin (\theta+d \theta)$

$-P \sin (\theta)=\rho A d x \frac{\partial^{2} w}{\partial t^{2}}$

$(\mathrm{M}+\mathrm{dM})-(\mathrm{V}+\mathrm{dV}) \mathrm{dx}+\mathrm{fdx} \frac{\mathrm{dx}}{2}-\mathrm{M}=0$

where $M(x, t)$ is the bending moment, $V(x, t)$ is the shear force, $f(x t)$ is the external lateral force per unit tube length, $P(x, t)$ is the axial force, $\theta$ is the inclination angle of tube center line, $x$ is the axial displacement and $\mathrm{w}$ is the lateral deflection of the tube. Furthermore, $\rho A=\rho_{t} A_{t}+\rho_{f} A_{f}$ where $\rho$ and $A$ are the mass density and cross-sectional area with subscripts $t$ and $f$ refers to the tube and fluid respectively. Small deflections, written as:

$$
\sin (\theta+d \theta) \cong \theta+d \theta=\theta+\frac{\partial \theta}{\partial x} d x=\frac{\partial w}{\partial x}+\frac{\partial^{2} w}{\partial x^{2}} d x
$$

Using the elementary beam bending theory, in combination with Eqs. (1) through (3), yields a single partial differential equation of motion for the system:

$$
\frac{\partial^{2} w}{\partial t^{2}}=\frac{1}{\rho A}\left[f(w, x, t)+P \frac{\partial^{2} w}{\partial x^{2}}-E I \frac{\partial^{4} w}{\partial x^{4}}\right]
$$

where, $E$ is the Young's modulus of elasticity and $I$ is the moment of inertia. Due to very low velocity of the fluid in the tube, its effect is considered negligible. The external forces acting on the tube can be expressed as:

$$
f(w, x, t)=F_{G}+F_{D}+F_{I}
$$

$F_{G}, F_{D}$ and $F_{I}$ represent gravity, damping and impact forces, respectively. The impact force originates from the contact of the tube with the borehole. The buoyancy force is the same magnitude as the fluid weight inside the tube, hence the gravity force is equal to the weight of the tube. The damping force is approximated using the following equation (Jansen 1993):

$F_{D}=-C_{h}|\dot{w}| \dot{w}$ where $C_{h}=\frac{2}{3 \pi} \rho_{f} C_{D} d_{o} l$

Here $C_{h}, \dot{w}, \rho_{f}, C_{D}, d_{o}$, and $l$ represent the hydrodynamic damping coefficient, lateral speed of the tube, fluid density, drag coefficient, outer diameter and length of tube. The impact force originates due to the tube/formation contact and is expressed as:

$$
\begin{gathered}
F_{I}=-k\left|w-C_{u}\right| \text { if } w>c_{u} \text { or }=k\left|w-C_{L}\right| \\
\text { if } w<c L \text { or }=0 \text { otherwise }
\end{gathered}
$$


where, $k, C_{u}$ and $C_{L}$ denote the formation stiffness (constant), of the upper and lower hole clearances, respectively. Equation (4) in conjunction with Eqs. (5) to (7) becomes a nonlinear partial differential equation. The solution of the governing equation requires initial and boundary conditions, which are given below:

$$
\begin{gathered}
\frac{\partial \mathrm{w}}{\partial \mathrm{x}}(0, \mathrm{t})=\mathrm{w}(0, \mathrm{t})=0, \frac{\partial^{2} \mathrm{w}(\mathrm{L}, \mathrm{t})}{\partial \mathrm{x}^{2}}=\frac{\partial^{3} \mathrm{w}(\mathrm{L}, \mathrm{t})}{\partial \mathrm{x}^{3}}=0 \\
\mathrm{w}(\mathrm{x}, \mathrm{t})=\frac{\partial \mathrm{w}}{\partial \mathrm{t}}(\mathrm{x}, \mathrm{t})=0 \quad \text { at } x, t=0
\end{gathered}
$$

\section{Numerical Solution}

The governing equation describing the dynamics of tube sagging along with the boundary and initial conditions is solved numerically using Method of Lines (Schiesser 1991) with a uniform x-grid and finite difference approximations for $\mathrm{x}$-derivatives. The spatial discretization reduces the partial differential equation into a set of time dependent nonlinear ordinary differential equations. The number of equations increases as the tube penetrates into the formation. The resulting set of differential equations is stiff in nature and a special solver is used to obtain the solution. Let $x_{o}, x_{1}, x_{2}, \ldots, x_{N}$ represent the nodal points along $\mathrm{x}$-axis, where $x_{o}$ and $x_{N}$ are the nodal points at the clamped and free end of the tube. Using backward and central difference schemes to approximate derivatives at the fixed end and all other nodal points in spatial discretization, the following can be written:

$$
\begin{gathered}
\left(\frac{\delta w}{\delta x}\right)_{o}=\frac{w_{0}-w_{-1}}{\Delta x}=0 \quad \text { which yields } \\
w_{0}=w_{-1}=0
\end{gathered}
$$

Where subscripts ' 0 ' and ' -1 ' refer to the node at the clamped end and the node preceding the clamped end. Use of the other two boundary conditions of Eq. (8) gives:

$$
\begin{aligned}
& \left(\frac{\partial^{2} w}{\partial x^{2}}\right)_{N}=\frac{w_{N-1}-2 w_{N}+w_{N+1}}{\Delta x^{2}}=0 \quad \text { and } \\
& \left(\frac{\partial^{2} w}{\partial x^{3}}\right)_{N}=\frac{w_{N+2}-2 w_{N+1}+2 w_{N-1}-w_{N-2}}{2 \Delta x^{3}}=0
\end{aligned}
$$

which yields $w_{N+1}=2 w_{N}-w_{N-1}$ and $w_{N+2}=4 w_{N}$ $w_{N-1}+w_{N-2}$. Similarly, for node 'i', one can be written

$$
\begin{aligned}
& \left(\frac{\partial^{2} w}{\partial x^{2}}\right)_{i}=\frac{w_{i+1}-2 w_{i}+w_{i-1}}{\Delta x^{2}} \text { and } \\
& \left(\frac{\partial^{4} w}{\partial x^{4}}\right)_{i}=\frac{w_{i+2}-4 w_{i+1}+6 w_{i}-4 w_{i-1}+w_{i-2}}{\Delta x^{4}}
\end{aligned}
$$

Substituting the above equations in Eq. (4) gives:

$$
\frac{\partial^{2} w_{i}}{\partial t^{2}}=\frac{1}{\rho A}\left[\begin{array}{l}
f\left(w_{i}, x_{i}, t\right)+\frac{P}{\Delta x^{2}}\left(w_{i+1}-2 w_{i}+w_{i-1}\right)- \\
\frac{E I}{\Delta x^{4}}\left(w_{i+2}-4 w_{i+1}+6 w_{i}-4 w_{i-1}+w_{i-2}\right)
\end{array}\right]
$$

Letting ' $y$ ' represents thevector containing the deflection and its time derivative at 'xi', where $\mathrm{i}=1,2$, ... $\mathrm{N}$, and ' $\mathrm{N}$ ' is the total number of discretization points ie.

$$
y=\left[w_{1} w_{2} \ldots w_{N} \frac{\delta w_{1}}{\delta} \frac{\delta w_{2}}{\delta t} \ldots \frac{\delta w_{N-2}}{\delta t} \frac{\delta w_{N-1}}{\delta t} \frac{\delta w_{N}}{\delta t}\right]^{T}
$$

Using Eq. (10), a matrix representation of the resulting set of nonlinear ordinary differential equations is used to obtain the solution:

$$
\dot{y}_{2 N \times 1}=A_{2 N \times 2 N} y_{2 N \times 1}+B_{2 N \times 1}
$$

Due to the fact that the problem is "stiff", an implicit method is used to obtain the solution. The code is written in MATLAB software, which starts with one node point representing the free and as it penetrates the formation. The simulation starts with zero slope and deflection at the free end as an initial condition, ie., $y^{(1)}(t=0)=\left[\begin{array}{ll}0 & 0\end{array}\right]^{T}$. The solution progresses in time to determine the deflection and slope vector at node 'I':

$$
y^{l}(t)=\left[\begin{array}{ll}
w_{l}^{l}(t) & \frac{\partial w_{1}^{l}}{\partial t}(t)
\end{array}\right]^{T}
$$

Assuming a constant rate of penetration, the tube penetrates distance $\Delta \mathrm{x}$ into the formation in a quasistatic mode. To proceed further with drilling, another node point is added, resulting in an increase in the number of equation by two (one each for deflection and slope). A new initial ' $y$ ' vector is generated using previous initial condition and the current solution at node ' 1 '. The algorithm continues until required penetration is reached.

\section{Results and Discussions}

The mathematical model developed for water jet drilling systems is simulated in MATLAB software based on the approach described in the previous section. In particular, the study focuses on predicting the tube sagging which results when the water jet deviates from its desired horizontal trajectory. The drilling 
where $A=\left[A_{1} A_{2}\right]^{T}$. Matrix $A_{2}$ is given below $A_{1}=\left[(O)_{N x N}\right]$ with 'O' and 'I'

$$
\left[\begin{array}{cccccccccccccc}
-2 \alpha-6 \beta & \alpha+4 \beta & -\beta & 0 & 0 & . & . & . & & & & & \\
\alpha+4 \beta & -2 \alpha-6 \beta & \alpha+4 \beta & -\beta & 0 & 0 & . & . & . & & & & \\
-\beta & \alpha+4 \beta & -2 \alpha-6 \beta & \alpha+4 \beta & -\beta & 0 & 0 & . & . & . & & & \\
0 & -\beta & \alpha+4 \beta & -2 \alpha-6 \beta & \alpha+4 \beta & -\beta & 0 & 0 & . & . & . & & \\
& & & & . & . & . & . & & & & & \\
& & & & & . & . & 0 & 0 & -\beta & \alpha+4 \beta & -2 \alpha-6 \beta & \alpha+4 \beta & -\beta \\
& & & & . & . & . & 0 & 0 & -\beta & \alpha+4 \beta & -2 \alpha-5 \beta & \alpha+2 \beta \\
& & & & & . & . & . & 0 & 0 & -2 \beta & 4 \beta & -2 \beta
\end{array}\right]
$$

represent null and identity matrices. The constant $\alpha=\frac{\mathrm{P}}{\rho \mathrm{A} \Delta \mathrm{x}^{2}}$ and $\beta=\frac{\mathrm{EI}}{\rho \mathrm{A} \Delta \mathrm{x}^{4}}$, while the vector $[\mathrm{B}]$ can be written as:

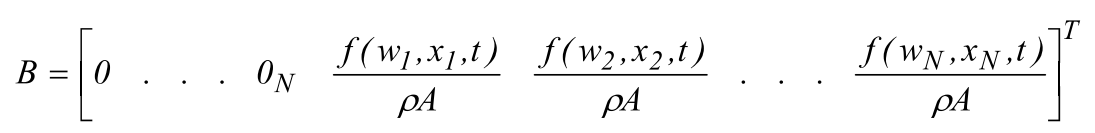

fluid is water with a density of $1000 \mathrm{~kg} / \mathrm{m}^{3}$. The outer diameter and thickness of the tube are $31.75 \mathrm{~mm}$ and $3 \mathrm{~mm}$, respectively. The tube material is steel with $\mathrm{E}=200 \mathrm{GPa}$ and $\rho=7830 \mathrm{~kg} / \mathrm{m}^{3}$. The initial clearance between tube and borehole is $5 \mathrm{~mm}$. The clearance is a function of the formation properties and nozzle design parameters such as the water jet diameter and the twist that is used to spin the drilling fluid inside the nozzle. Figure 2 shows the profile(with upper and lower boundaries) of the drilled hole obtained from simulation in absence of thrust force $(\mathrm{P}=0 \mathrm{kN})$. It is obvious from the figure that drilling starts horizontally but later sinks down due to the sagging phenomenon. As soon as the tube centerline deflects from the horizontal reference and transients are diminished, and the drilled hole significantly deviates from the desired borehole trajectory. It is also clear from the figure that the drilled hole profile is not smooth due to cavitation of the nozzle. The lateral vibration of the nozzle is the major of cause of this behavior. To ascertain this, the lateral movement of tube centerline at three specific nodes is plotted in Fig. 3. These nodes are chosen near the clamped, middle and nozzle ends. The mean position of clamped end node remains horizontal indicating negligible lateral motion. Contrary to this, the middle and end nodes have significant lateral motion exceeding tube-hole clearance resulting in frequent impact with lower boundary of the drilled hole. However due to sagging phenomenon, the lateral movement of the drilling tube is considerably reduced until it stays in constant contact with lower boundary of the drilled hole. For systems, where the drilling tube is kept under tension due to the pressure difference across the nozzle, the thrust force is not negligible. In order to see the effect of thrust force on the profile of the drilled hole, simulations were carried out for $10 \mathrm{kN}$ and $20 \mathrm{kN}$ of thrust force as shown in Figs. 4(a) and 4(b) respectively. As the magnitude of thrust force increased, the profile become more irregular. In case of $20 \mathrm{kN}$ thrust force (Fig. 4(b)), the borehole profile was highly irregular, which is unacceptable from an application point of view. In order to alleviate this problem, a closed loop controller must be designed to assure that the drilled borehole is straight and does not sag or have a highly irregular profile. The following paragraphs discuss the design and implementation of a control system for the drilling system.

In order to control the system, nonlinear inverse control method is used for Eq. (4) to design a controller to minimize the sagging problem. For this purpose, a control force $\mathrm{u}(\mathrm{t})$, is applied at the nozzle end. The addition of the control force modifies the boundary condition i.e., the shearing force must be equal to the control force $\mathrm{u}(\mathrm{t})$. Also, the equation of motion for the last node ' $\mathrm{N}$ ' modifies to:

$$
\frac{\partial^{2} w_{N}}{\partial t^{2}}=\frac{1}{\rho A}\left[\begin{array}{l}
f\left(w_{N}, x_{N}, t\right)-\frac{E I}{\Delta x^{4}} \\
\left(2 \Delta x^{3} u(t)+2 w_{N}-4 w_{N-1}+2 w_{N-2}\right)
\end{array}\right]
$$

The control force, $u(t)$, is chosen to cancel the undesired terms in the above equation and a new control variable $\mathrm{v}(\mathrm{t})$ is introduced to have the desired dynamics for node ' $\mathrm{N}$ ' i.e.,: 
T Pervez, SA Al-Hiddabi, A Al-Yahmadi and AC Seibi

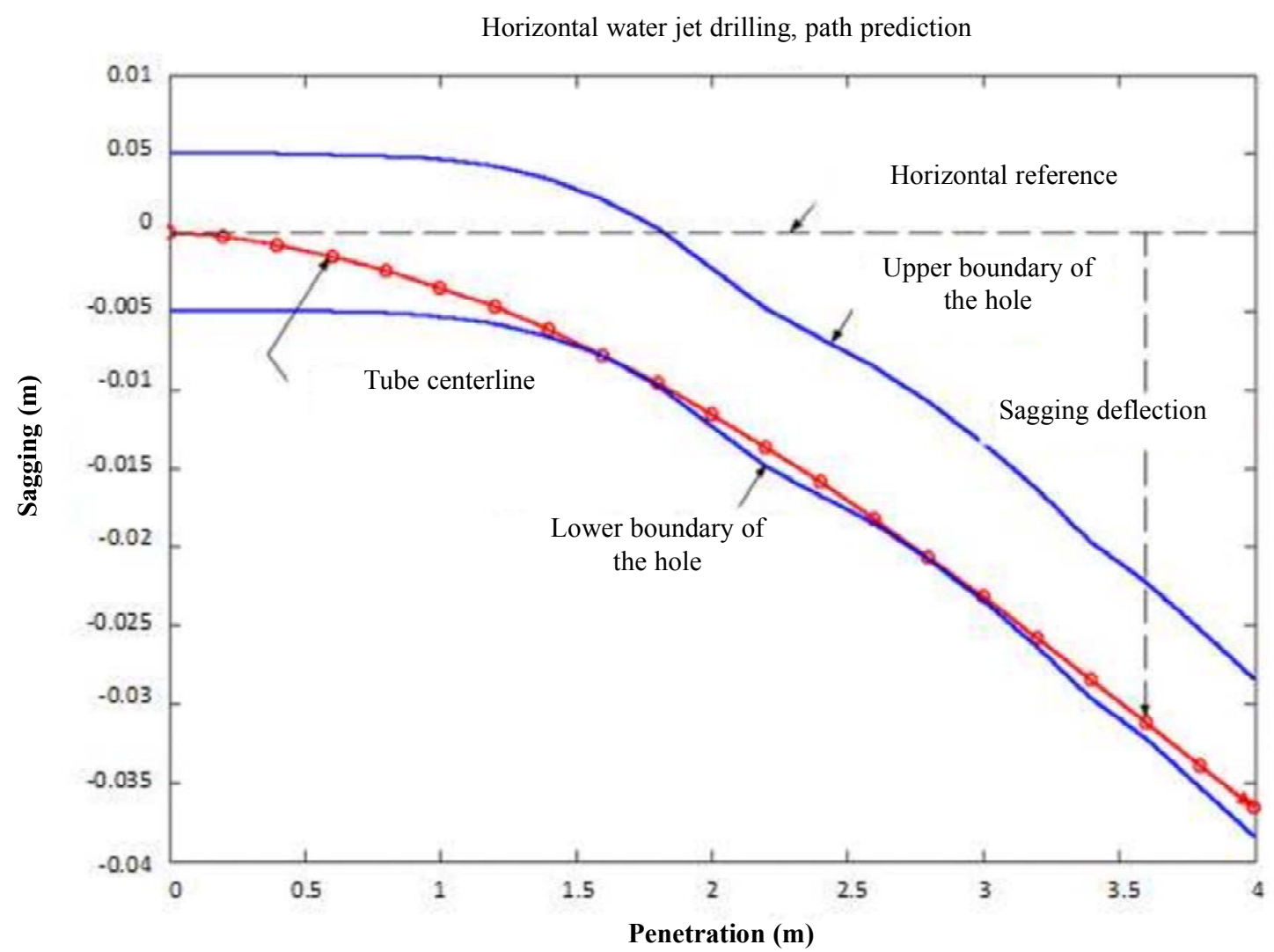

Figure 2. Drilled hole profile obtained from simulation

x $10^{3}$ Oscillation of three different points on the drillstring showing impact with hole

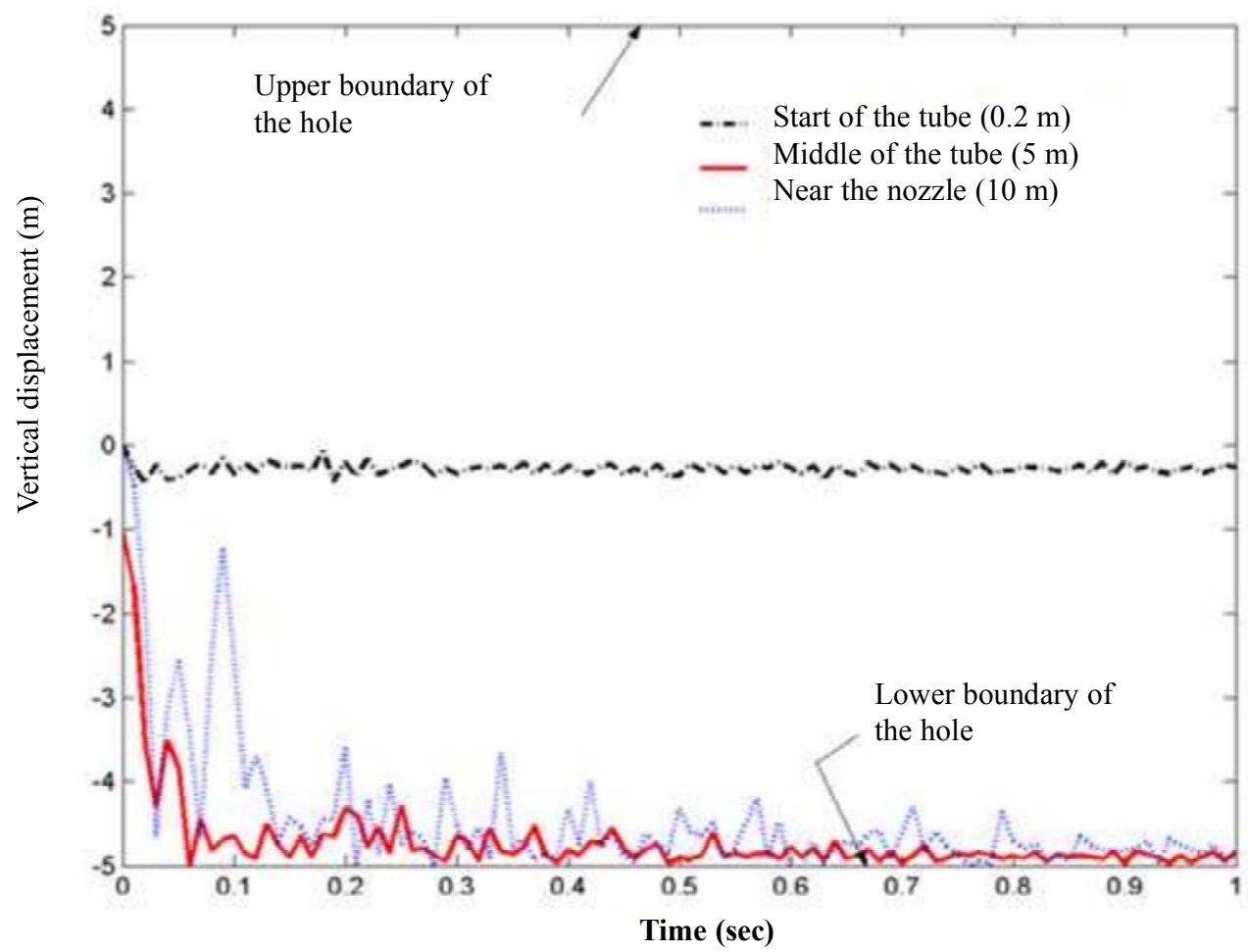

Figure 3. Impact of the drilling tube (start, middle and near nozzle end) with the hole boundary 

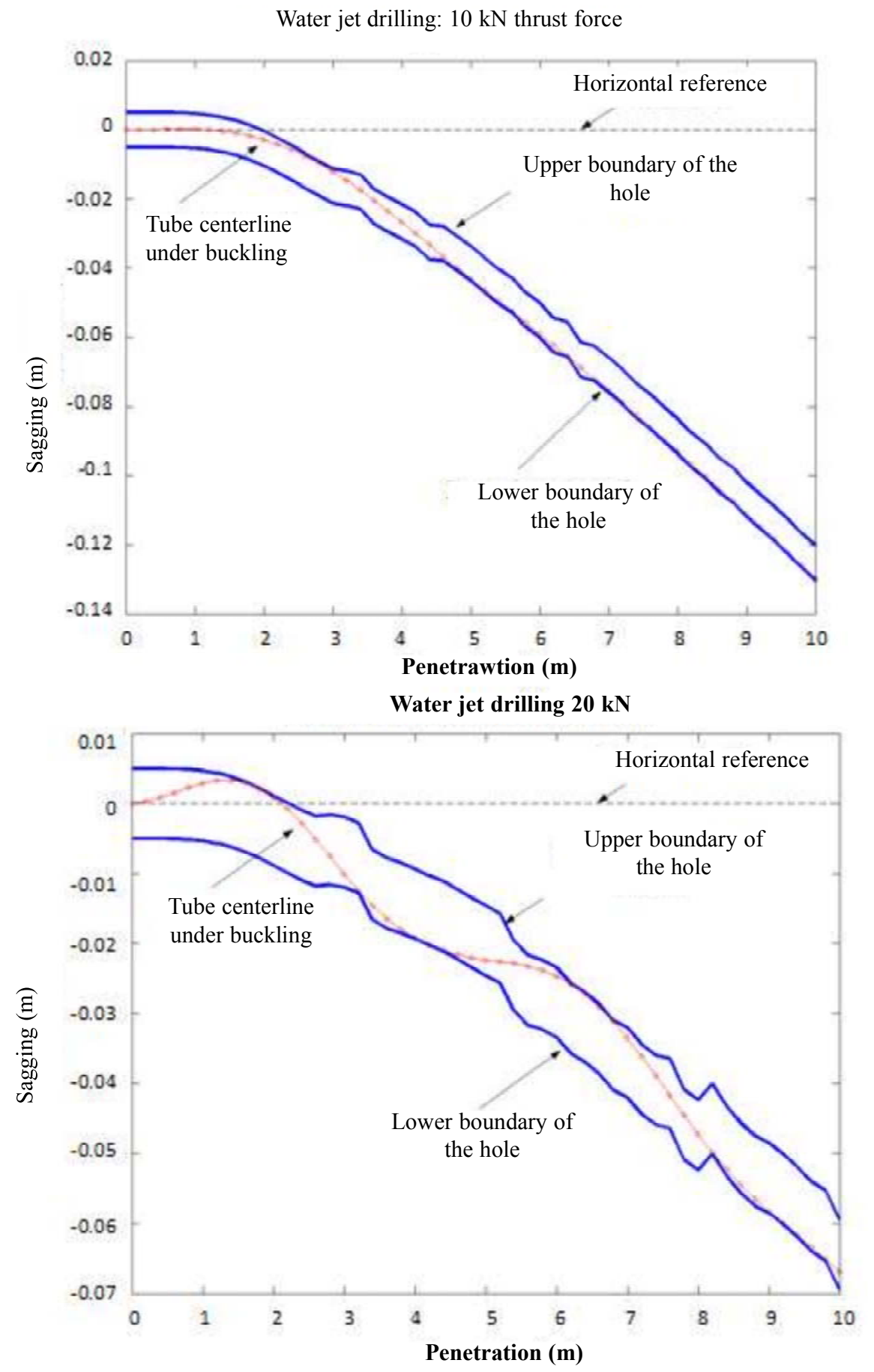

Figure 4. Effect of thrust force on the profile of drilled hole and tube buckling at (a) $\mathrm{P}=10 \mathrm{kN}$, (b) $\mathrm{P}=20 \mathrm{kN}$

$$
v(t)=-k_{2} \dot{w}_{N}-k_{1} w_{N}
$$

Where constants $k_{1}$ and $k_{2}$, termed as controller gains, must be selected so that the characteristic equation has roots with negative real parts. Moreover, the values of $k_{1}$ and $k_{2}$ can be chosen to have the desired dynamics for the last node. For full compensation, $u(t)$ is selected as:

$$
u(t)=\frac{\Delta x}{2 E I}\left[\begin{array}{c}
f\left(w_{N}, x_{N}, t\right)-\frac{E I}{\Delta x^{4}}\left(2 w_{N}-4 w_{N-1}\right. \\
\left.+2 w_{N-2}\right)-\rho A v
\end{array}\right]
$$

Figure 5 shows the profile of drilled hole using full compensation control having gains of $k_{1}=871$ and $k_{2}$ $=1742.5$. The settling time of the water-jet drilling 


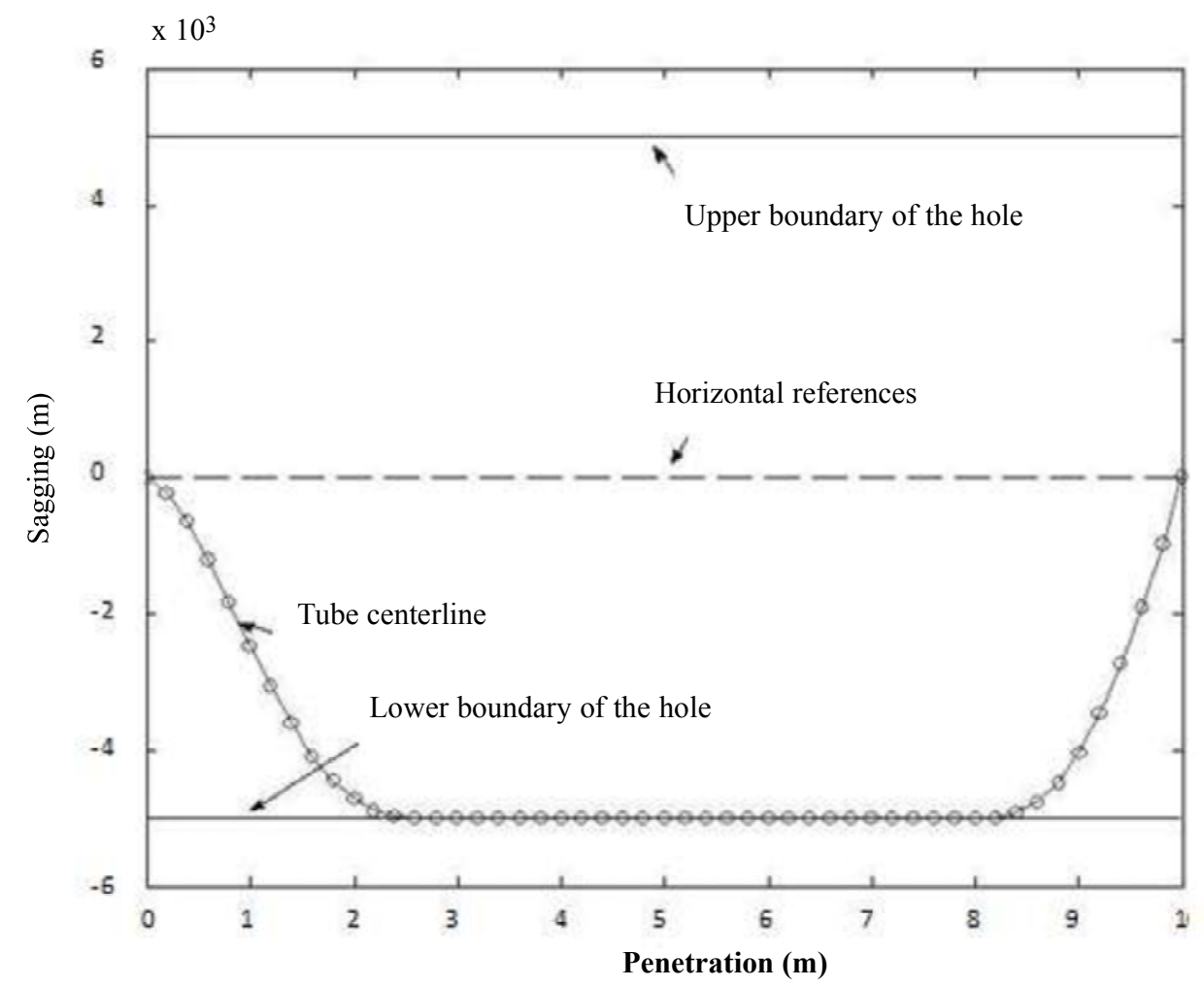

Figure 5. Drilled hole profile with full compensation controller with gains $k_{1}=871$ and $k_{2}=1742.5$

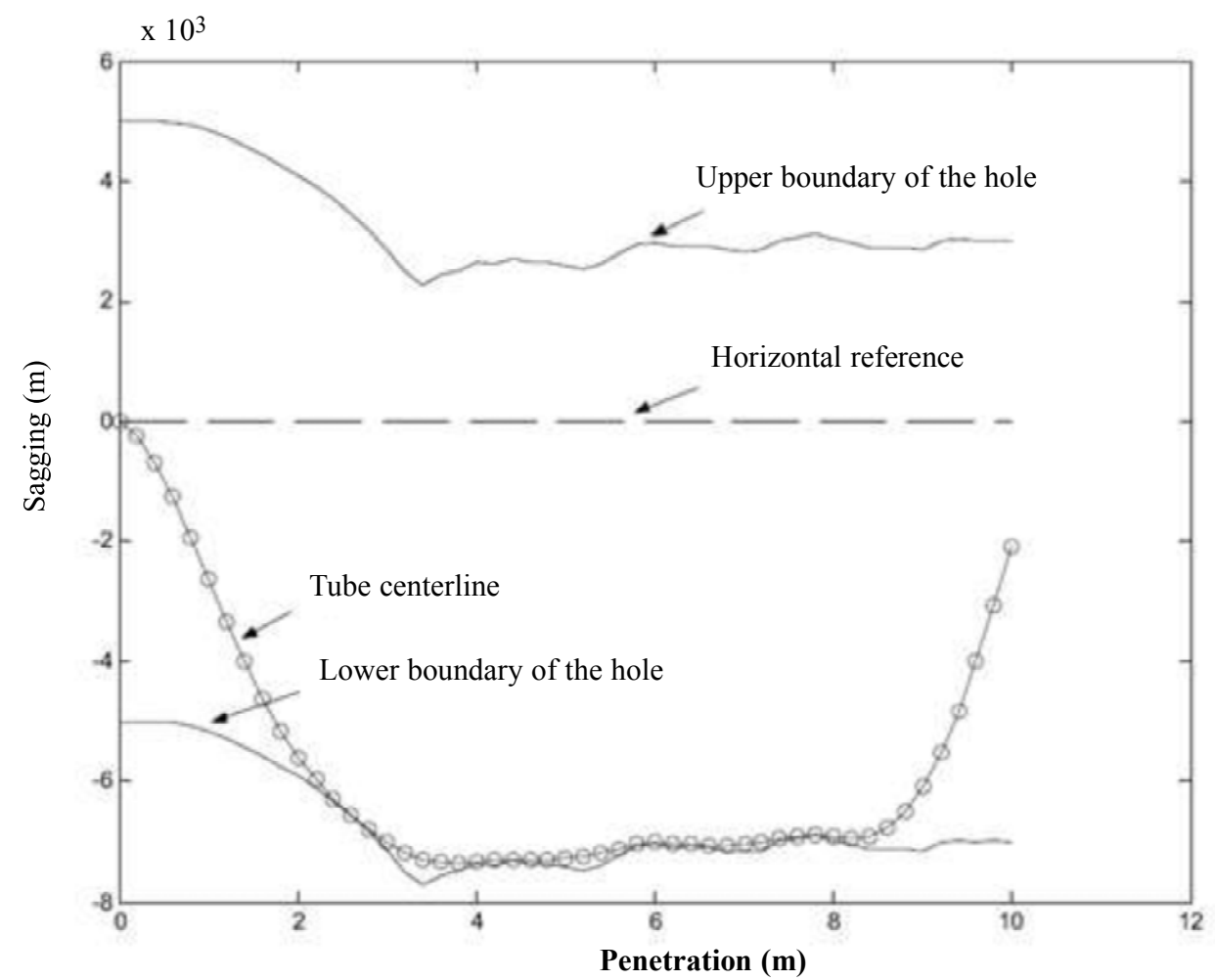

Figure 6. Drilled hole profile with partial compensation controller with gains $k_{1}=871$ and $k_{2}=1742.5$

system with full compensation controller is $0.2 \mathrm{sec}-$ onds. It is clear from the figure that the deviation in the drilled hole from the desired hole trajectory is negligible. The front end of the tube is maintained along 
the desired trajectory by the controller while the portion of the tube between the clamped and nozzle ends rests on the lower boundary of the drilled hole. The above control law requires the function $f\left(w_{N}, x_{N}, t\right)$ which might be difficult to obtain in actual applications. Hence, a partial compensation control which does not require this function is also used to determine the profile of the drilled hole as shown in Fig. 6. The same values of $k_{1}$ and $k_{2}$ are used. This controller does not require the position information of the two nodes preceding the last node. However, the drilled hole profile is not regular and partially deviates from desired trajectory as shown in Fig. 6.

\section{Conclusions}

A closed-form solution is obtained to predict the path of the drilled hole and associated sagging in orizontal water-jet drilling process incorporating gravity, damping and impact forces. It is found that in absence of a controller the drilled hole has irregular profile and sags more than $20 \mathrm{~mm}$ for $3 \mathrm{~m}$ of penetration. The variation in thrust from $10 \mathrm{kN}$ to $20 \mathrm{kN}$ results in unacceptable hole profile and trajectory for field applications. In addition, the amount of sagging reaches to more than $4 \mathrm{~m}$ for $400 \mathrm{~m}$ length of penetration, which results in missing the thickness of oil-sands in shallow oil fields. Therefore, the use of uncontrolled water jetting system for drilling long sidetracks is not possible. However, adding full compensation controller with gains of $\mathrm{k}_{1}=871$ and $\mathrm{k}_{2}=1742.5$, the drilled hole trajectory remains within the set clearance of $5 \mathrm{~mm}$. The drilling tube-nozzle systems settles within 0.2 seconds and desired trajectory and profile of drilled can be attained by adjusting the controller gains. These gains can be set to different values depending on nozzle dynamics, clearance between tube and hole, and material properties of tube and formation.

\section{References}

Buset P, Riiber M, Eek A (2001), Jet drilling tool: Cost-effective lateral drilling technology for enhanced oil recovery. SPE 68504, SPE Coiled Tubing Roundtable, USA.

Dickinson W, Pesavento MJ, Dickinson RW (1990), Data acquisition, analysis and control while drilling with horizontal water jet drilling systems. CIM/SPE \# 90-127, Canada.

Fair C (1998), Development of high pressure abrasive jet drilling. SPE of AIME, USA.

Halliburton Case History (2009), Short-radius drilling technology enhances production in depleted field. Case History \# HO1770.

Jansen JD (1993), Nonlinear dynamics of oilfield drillstrings. Ph.D Thesis, Delft University.

Kolle JJ (1998), Water and abrasive jetting, and mechanical techniques expedite hard rock drilling. Oil and Gas Journal 96(16):90-94.

Kolle JJ, Marvin MH (2000), Jet-assisted coiled tubing drilling with supercritical carbon dioxide. Proceedings of ETCE/OMAE2000 Joint Energy Conference, New Orleans, USA.

LaPrade JD (2000), Slim hole rotary steerable shortradius horizontal drilling system. 8th International Williston Basin Horizontal Well Workshop, North Dakota, USA.

Stoner MS (1999), Hole deviation is defined. Denver SPE Drilling Study Group Meeting, USA.

Schiesser WE (1991), The numerical method of lines integration of partial differential equations. Academic Press, San Diego, USA.

Tabatabaei M, Ghalambor A (2009), A new method to predict performances of horizontal and multilateral wells. IPTC Paper \# 13122, Doha, Qatar.

Zhu H (2009), Development and trend of underbalanced drilling technology. Petroleum Geology and Engineering 23(2):80-82. 